\title{
ANALYSIS OF HEAT SPREADING PERFORMANCE OF ACETONE-FILLED HEAT PIPE AT LOW TEMPERATURES FOR USING IN SATELLITE HONEYCOMB PANELS
}

\author{
Valeri V. Vlassov \\ National Institute for Space Research (INPE/DMC) \\ S.J.Campos, SP, Brazil \\ vlassov@dem.inpe.br
}

\begin{abstract}
HP) performance under low temperatures is theoretically studied. The developed mathematical model describes the HP behavior under conditions when locations of the evaporator and condenser sections are not defined a priori and can eventually be changed during the HP operation. Typical application of such a HP configuration is the thermo-stabilized structural honeycomb panel of satellites. Usually the ammonia is used in these HP applications; however the acetone is investigated as a low hazardous alternative of the working fluid. This paper aims to examine how the acetone HP will perform under cold conditions close to the viscous and sonic limits. Once the limit is violated, the spots of local dry-out occur. The numerical algorithm used in the model is based on the control volumes approach. Energy balance on the equipment-panel level is solved in conjunction with the working fluid momentum and mass conservation along HP axial direction. Dynamic variations of wetting angle and groove flooding are taken into account. The scenarios of normal operation, start-up, local dry-out and warming up are investigated.
\end{abstract}

Keywords: heat pipe, mathematical model, honeycomb panel, operation limit

\section{Introduction}

Heat pipes (HPs) were used in thermal control of satellites for since 70's. The HPs are very appropriate devices for space application, because they do not need electric power for operating, do not include moving parts, have an exceptional heat transport capability and, if a proper technology is established, have a long operational life. The HPs are also used for spreading the heat of the dissipating equipments over the structural panels; they are typically attached to or embedded in the honeycomb panel. For such applications the ammonia-filled aluminum groove heat pipes are commonly used. In spite of having the attractive thermo-physical properties, ammonia is a high-pressure and hazardous fluid and relies on safety-certified expense technology. INPE adopted a research program CONTER, which includes the development of two-phase technology employing low-pressure and low hazardous acetone as an alternative working fluid. Acetone heat pipes already have been used in thermal control of the Mageon 4 and 5 satellites, being in operation for more than 4 years (Baturkin et al., 2002). Acetone-filled heat pipe radiator assemblies present very competitive design mass characteristics against ammonia for the same HP heat transport capability (Vlassov et al., 2006).

Heat pipes designed for space applications must operate under very different ambient conditions. Two extreme orbital cases must be usually considered: extreme cold and hot operational conditions. The cold condition corresponds to longest eclipse orbits at summer solstice and minimal heat dissipation of the on-board equipment, while the hot condition corresponds to shortest eclipse time at winter solstice and maximum heat dissipation of equipment. Some additional cases including contingencies should be also considered depending of the specific satellite configuration, orbital parameters, operation and emergency satellite modes. Ground tests are unable to adequate reproduce the HP operational conditions at 0 -g. Therefore, the mathematical modeling is important to predict correctly the HP performance under different flight conditions.

Complete mathematical model of the HP embedded in a panel should combine the conjugate processes of the two-phase heat and mass transfer inside the heat pipe and the high-level energy balance, which includes equipment heat dissipation and the effects due to the external heat fluxes variations. Most of the studies performed in this area up to now, were devoted to the mathematical modeling of local processes, particularly the evaporation or condensation in porous structures and in micro-grooved channels, or 2D vapor flow in the HP core. Although some complex steady state and transient HP mathematical models have been developed (Tournier and El-Genk, 1994; Mikheyev et al., 2002; Faghri, 1995), they are not appropriate for using in the practice of thermal control systems design. The shortcomings are the following: the boundary conditions related to heat application are canonical, i.e. evaporator is on one end and condenser - on another; internal vapor-liquid interface is stable (no dry-out, no local over-flooding, neither liquid priming deficit); structure of the HP submodel does not adequate for inserting in the entire thermal model of satellite; complex numerical algorithms consumes substantial computation time. 
From another hand, the reduced HP engineering 1D models, developed in the 1970s (Chi, 1976; Bienert et al., 1972), still meet the design purposes. These models, in spite of being simple and numerically effective , fit well the experimental data, particularly for axially-grooved HPs that have well-determined geometry (R.Schlitt, 1975; Faghri, 1995). Nevertheless, this type of models does not deal with any operational anomalies and temporary failures which could happen with HPs in real situations.

The proposed mathematical model extents the $1 \mathrm{D}$ model in order to tackle with operational anomalies and particularities of internal phase distribution, keeping the proved precision in normal mode. Besides, the developed mathematical model simulates transient HP performance in the conditions when either length or locations, or number of evaporator and condenser sections do not known a priori and may be eventually changed during the HP operation. In the model, axial-distributed profiles of temperatures, mass flow rate pressure, wetting angle and degree of groove flooding are calculated in response of heat load and external conditions variations. A dedicated procedure transforms the internal "floating point" HP boundary conditions to the left-side boundary conditions in order to permit the numerical integration by a well-proved technique for ordinary differential equations.

The peculiarity of the model presented in this paper comprises the feature that the prime driven mechanism of the axial liquid flow is defined as a function of grooves flooding with liquid. The capillary pressure is developed by meniscus curvature alteration due to change in the degree of grooves flooding, caused by local evaporation or condensation or by other factors. This imposed capillary pressure field provokes liquid movement in the grooves along HP axis. The re-dislocation of liquid causes the changes in the flooding and, consequently, in capillary pressure. By this manner, the capillary pressure field and axial liquid velocity field adjust each other. When flooding is a main driving variable in a HP model, such phenomena as the start-up, partial dry-out, rewetting, opposite flows and local over-flooding can be naturally simulated without any modification of the model structure and additional suggestions. This approach in the modeling differs with the usual approach in which the degree of flooding is omitted, and the liquid velocity field is calculated from the mass balance. After that the liquid pressure field is obtained from the axial momentum conservation using the reference saturation pressure in the condenser end. Capillary pressure is used only for checking whether the capillary limit was violated.

The present study was performed in attempt to answer the practical question, how the panel with acetone HP will perform at low temperatures under cold conditions against ammonia HP. Because of low acetone vapor density compared to ammonia, the cold temperature condition may bring the acetone HP to operate close to its viscous and sonic limits. Once the limit violated, spots of local dry-out occur. Different scenarios of operation including local partial dry-out, re-wetting and start-up are simulated and investigated.

The developed model is also used as a base to build a Thermal DeskTop /SINDA-FLUINT sub-model of HP honeycomb structural panel for the CBERS China-Brazilian satellite.

\section{Nomenclature}

\begin{tabular}{|c|l|}
\hline Symbol & \\
\hline $\mathrm{A}$ & area $(\mathrm{m})$ \\
\hline $\mathrm{a}$ & dimensionless groove aspect ratio \\
\hline $\mathrm{C}$ & specific heat $(\mathrm{J} / \mathrm{kg})$ \\
\hline $\mathrm{D}$ & diameter $(\mathrm{m})$ \\
\hline$\tilde{f}$ & shear stress gradient $(\mathrm{Pa} / \mathrm{m})$ \\
\hline $\mathrm{f}$ & dimensionless factor in $(\mathrm{fRe})$ \\
\hline $\mathrm{G}$ & thermal conductance $(\mathrm{W} / \mathrm{K})$ \\
\hline $\mathrm{g}$ & specific thermal conductance $\left(\mathrm{W} / \mathrm{K} / \mathrm{m}^{2}\right)$ \\
\hline $\mathrm{j}$ & heat transfer coefficient $\left(\mathrm{W} / \mathrm{K} / \mathrm{m}^{2}\right)$ \\
\hline $\mathrm{K}$ & specific mass flow rate $\left(\mathrm{kg} / \mathrm{s} / \mathrm{m}^{2}\right)$ \\
\hline $\mathrm{k}$ & permeability (m $\left.{ }^{2}\right)$ \\
\hline $\mathrm{L}$ & thermal conductivity $(\mathrm{W} / \mathrm{K} / \mathrm{m})$ \\
\hline $\mathrm{m}$ & length $(\mathrm{m})$ \\
\hline $\mathrm{M}$ & mass $(\mathrm{kg})$ \\
\hline$\dot{m}$ & mass of fluid in HP $(\mathrm{m})$ \\
\hline $\mathrm{N}$ & mass flow rate $(\mathrm{kg} / \mathrm{s})$ \\
\hline $\mathrm{n}$ & number of grooves in $\mathrm{HP}$ \\
\hline $\mathrm{P}$ & dimensionless gravity overload \\
\hline $\mathrm{Q}$ & pressure $($ Pa) \\
\hline
\end{tabular}




\begin{tabular}{|c|c|}
\hline$q$ & heat flux $\left(\mathrm{W} / \mathrm{m}^{2}\right)$ \\
\hline $\mathrm{t}$ & "fast" time (s) \\
\hline $\mathrm{T}$ & temperature $(\mathrm{K})$ \\
\hline $\mathrm{V}$ & volume $\left(\mathrm{m}^{3}\right)$ \\
\hline $\mathrm{u}$ & axial velocity (m/s) \\
\hline $\mathrm{W}$ & width (m) \\
\hline $\mathrm{x}$ & coordinate (m) \\
\hline \multirow[t]{2}{*}{$\mathrm{y}$} & tilt (m) \\
\hline & Greeks \\
\hline$\delta$ & thickness (m) \\
\hline $\bar{\delta}$ & average thickness (m) \\
\hline$\Delta$ & difference operator \\
\hline$\varepsilon$ & porosity or emissivity \\
\hline$\lambda$ & latent heat of evaporation ( $\mathrm{J} / \mathrm{kg})$ \\
\hline$\mu$ & dynamic viscosity (Pa s) \\
\hline$\theta$ & wetting angle (deg.) \\
\hline$\rho$ & density $\left(\mathrm{kg} / \mathrm{m}^{3}\right)$ \\
\hline$\sigma$ & surface tension $(\mathrm{N} / \mathrm{m})$ \\
\hline$\tilde{\sigma}$ & Stefan-Boltzman constant $\left(\mathrm{W} / \mathrm{K}^{4} / \mathrm{m}^{2}\right)$ \\
\hline$\tau$ & "slow" time (s) \\
\hline \multirow[t]{2}{*}{$\xi$} & friction coefficient \\
\hline & Subscripts \\
\hline 0 & at laboratory conditions \\
\hline $\mathrm{b}$ & lateral inner panel sheet section \\
\hline $\mathrm{C}$ & capillary \\
\hline $\mathrm{e}$ & evaporator \\
\hline ext & external \\
\hline eq & equipment \\
\hline $\mathrm{h}$ & hydraulic \\
\hline $\mathrm{i}$ & index (element number along x) \\
\hline IR & infra-red \\
\hline if & at interface \\
\hline l & liquid \\
\hline $\mathrm{m}$ & number of equipment box \\
\hline mc & micro-film \\
\hline $\mathrm{p}$ & base of the HP grooves \\
\hline$r$ & bottom outer panel sheet section \\
\hline ref & reference point \\
\hline $\mathrm{q}$ & equipment \\
\hline $\mathrm{s}$ & solar \\
\hline sat & saturation \\
\hline $\mathrm{W}$ & wall \\
\hline $\mathrm{V}$ & vapor \\
\hline $\mathrm{x}$ & along HP axis \\
\hline $\mathrm{z}$ & orthogonal to HP wall, to center \\
\hline
\end{tabular}

\section{Basic layout and energy conservation}

The basic outline of the HP with possible vapor and liquid phase distributions for particular case of two heat loads is shown in Fig 1. The positions of heat loads and heat output sections are different from the canonical configuration, when HP is heated from one end section and cooled from another. When HP is used for heat spreading, as in satellite panels, the heat can enter from multiple locations along HP axis (upper arrow sets in Fig. 1). The heat output usually occurs along entire length of the HP if the panel is external (lower arrow sets), or/and from locations where other structural panels are attached. 


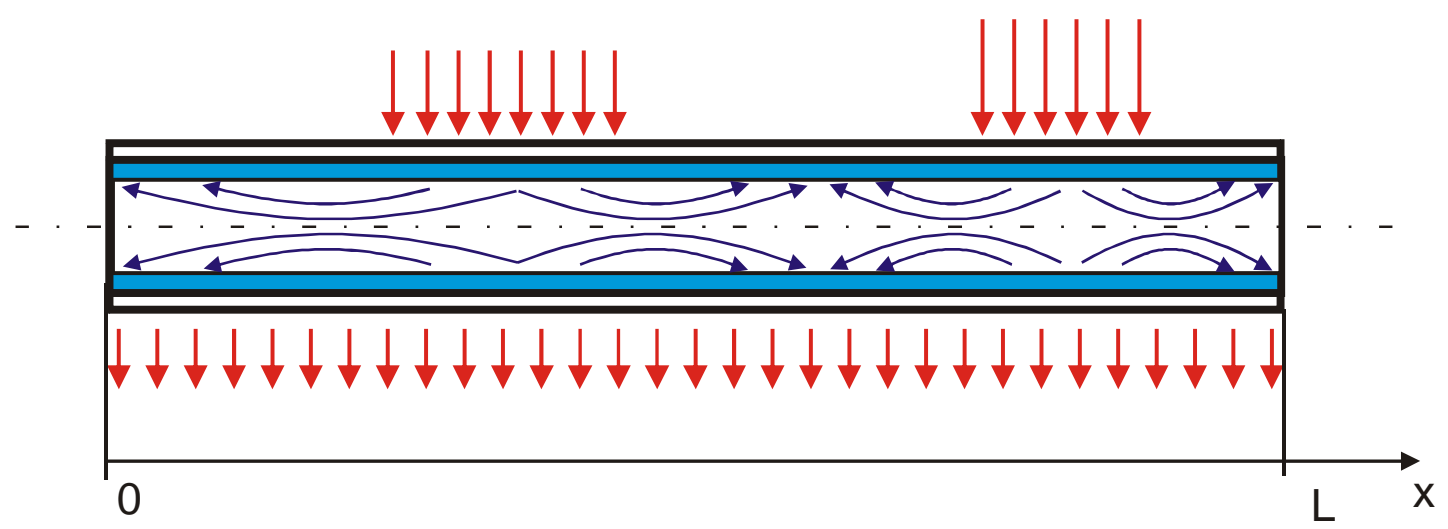

Figure 1. Possible phase distribution inside an axially-grooved HP.

Figure 2 demonstrates a typical layout of the panel with inserted HPs and mounted equipment, and a corresponding cross section of the assembly (not scaled). Model nodal layout and definition of temperatures are also shown in this figure. The nodes differ in their thermal capacity: the black-filled circles are the nodes with associated mass of the structure, and the not-black circles correspond to the arithmetic nodes, which represent fast processes of the HP internal heat and mass transfer.

In accordance with the 1D proven approach for the HP modeling, we perform the spatial discretzation of the panel fragment along the HP axis with $\Delta x_{i}$ step. The energy conservation of the panel fragment of the $\Delta x_{i}$ length can be written out as a set of ordinary differential equations. For $i$-th control volume, which includes a fragment of $m$-th equipment, the equation is as the following

$$
(C m)_{q m i} \frac{d T_{q m i}}{d \tau}=q_{q m i}(\tau) A_{q m i}-G_{q w m i}\left(T_{q m i}-T_{w i}\right)-G_{q m x i}\left(T_{q m, i-1}-T_{q m i}\right)-G_{q m x i}\left(T_{q m, i+1}-T_{q m i}\right)
$$

Here index $i$ runs within the range that corresponds to $m$-th box. The heat conductance along the $m$-th equipment box $\left(G_{q m x i}\right)$ is also considered because it contributes to the axial HP conductance.
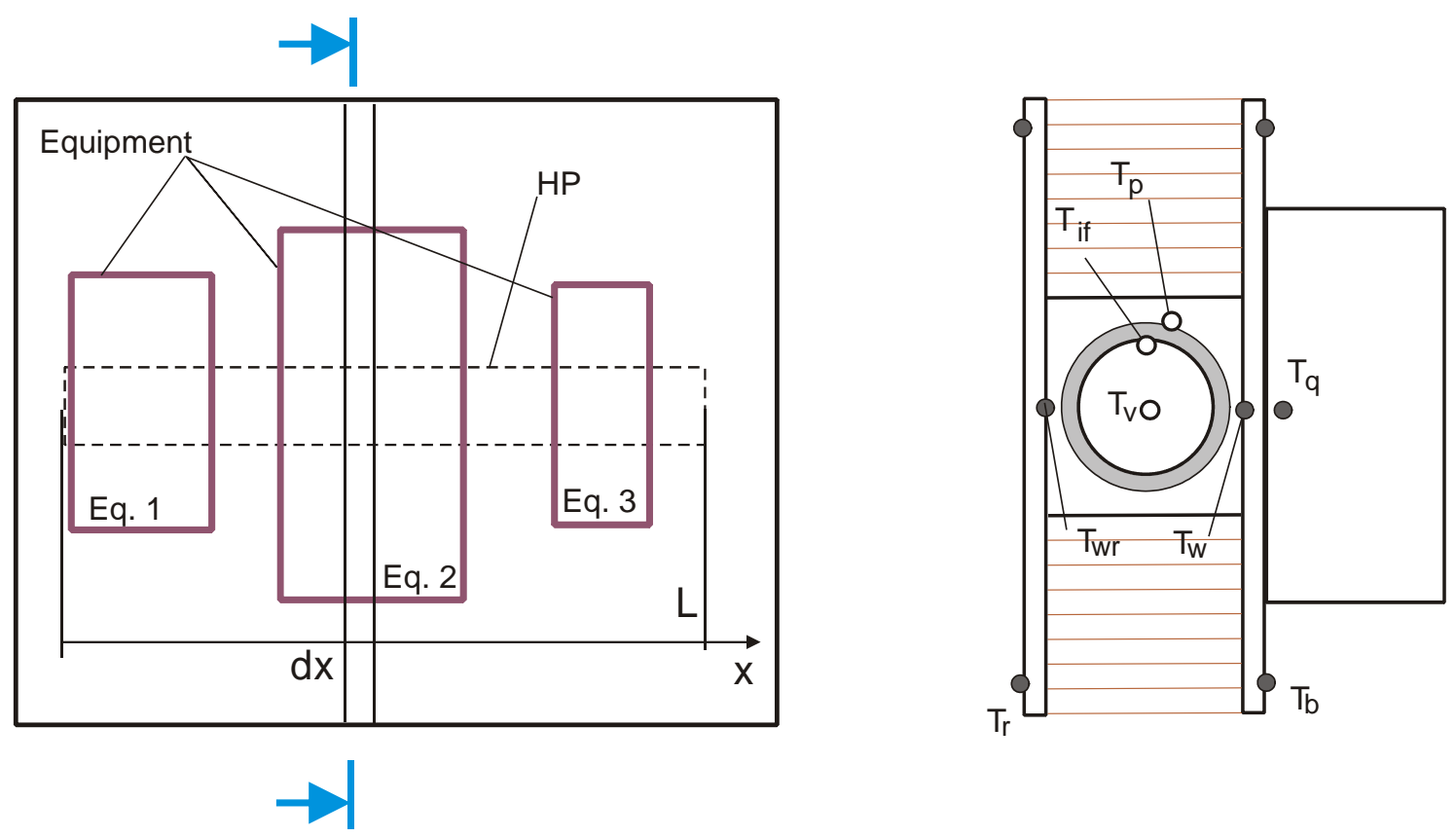

Figure 2. Panel layout and definition of temperatures in a cross-section.

Heat input from the equipment box and heat output to the HP wall and side sections of the panel define the energy balance of the right part of the HP casing (from the equipment side).

$$
\begin{gathered}
(C m)_{w i} \frac{d T_{w i}}{d \tau}=G_{q w i}\left(T_{q i}-T_{w i}\right)-G_{w b}\left(T_{w i}-T_{b i}\right)-G_{w p}\left(T_{w i}-T_{p i}\right)-G_{w x}\left(T_{w, i-1}-T_{w i}\right)- \\
G_{w x}\left(T_{w, i+1}-T_{w i}\right)+G_{w w}\left(T_{w r i}-T_{w i}\right)
\end{gathered}
$$


We assume that the right face of the honeycomb panel, as it shown in Fig. 2, looks the interior of the satellite and is insulated; however the left face is exposed to outer Space and receives the external flux from the Sun and the Earth. Thus, the energy balance for the external panel fragment is given by

$$
\begin{aligned}
(C m)_{w r i} \frac{d T_{w r i}}{d \tau}= & G_{w r p}\left(T_{p i}-T_{w r i}\right)-G_{w r b}\left(T_{w r i}-T_{r i}\right)+G_{w r x}\left(T_{w r, i-1}-T_{w r i}\right)+ \\
& G_{w r x}\left(T_{w r, i+1}-T_{w r i}\right)+G_{w w}\left(T_{w i}-T_{w r i}\right)+q_{e x t}(\tau) \Delta A_{i}-\varepsilon \tilde{\sigma} T_{w r i}^{4} \Delta A_{i}
\end{aligned}
$$

Where $\Delta A_{i}$ is the area of the panel corresponded to discretization step $\Delta x_{i}$. The side sections of the panel are also involved in the heat transfer:

$$
\begin{aligned}
(C m)_{b i} \frac{d T_{b i}}{d \tau}= & G_{w b}\left(T_{w i}-T_{b i}\right)-G_{b r}\left(T_{b i}-T_{r i}\right)-G_{b x}\left(T_{b, i-1}-T_{b i}\right)-G_{b x}\left(T_{b, i+1}-T_{b i}\right) \\
(C m)_{r i} \frac{d T_{r i}}{d \tau}= & G_{r b}\left(T_{w r i}-T_{r i}\right)+G_{b r}\left(T_{b i}-T_{r i}\right)-G_{r x}\left(T_{r, i-1}-T_{r i}\right)-G_{r x}\left(T_{r, i+1}-T_{r i}\right)+ \\
& +q_{e x t}(\tau) \Delta A_{i}-\varepsilon \tilde{\sigma} T_{r i}^{4} \Delta A_{i}
\end{aligned}
$$

Two-phase heat and mass transfer processes go much faster in the HP than the heat transfer in the panel structure, mainly due to the high thermal capacity of attached equipment. Consequently, the local heat balance on the liquid-vapor interface can be described by the following algebraic equation, which establishes that the heat flux coming from HP wall to the groove bottom region (temperatures $T_{p i}$ ) is equal to the heat flux, coming through the flooded grooves to the vapor-liquid interface.

$$
g_{w p}\left(T_{w i}-T_{p i}\right)=g_{p i f}\left(T_{p i}-T_{i f i}\right)
$$

The heat flux coming to or from the groove bottom to vapor-liquid interface (temperature $T_{i f i}$ ) feeds the processes of evaporation or condensation.

$$
g_{p i f}\left(T_{p i}-T_{i f i}\right)=\lambda j_{z i}
$$

The vapor-liquid interface temperature is associated to the vapor pressure by saturation conditions. We presume that the interface temperature profile along HP axis follows the current pressure profile, which is obtained from the momentum conservation. Therefore, in the numerical algorithm at each slow time step, new vapor-liquid interface temperature profile is obtained by shifting the previous-time-step profile on a way in which the following instant energy balance over entire HP is satisfied.

$$
\int_{0}^{L} \lambda j_{z} d x=\int_{0}^{L} g_{p i f}\left(T_{p}-T_{i f}\right) d x=0
$$

Equations (1-7) contain 9 unknowns associated with $i$-th HP cross section: $\left\{T_{e q i}, T_{w i}, T_{w r i}, T_{b i}, T_{r i}, T_{p 1 i}, T_{p 2 i}\right.$, $\left.j_{z i}, T_{i f i}\right\}$. Numerical equivalent of Eq. (8) provides auxiliary integral condition for all cross-sections. Additional conditions of momentum and mass balance in the HP should be considered to close the set of equations and to find the profiles of pressures and other parameters.

\section{Momentum and mass conservation in liquid phase}

Momentum conservation of liquid flowing through the HP grooves is expressed by

$$
\frac{\partial \dot{m}_{l}}{A_{l x} \varepsilon_{x} \partial t}=-\frac{\partial P_{l}}{\partial x}-\frac{\mu_{l} \dot{m}_{l}}{\rho_{l} K A_{l x} \varepsilon_{x}}-n g \rho_{l}-\tilde{f}_{l v}
$$

The permeability of the HP groove structure is defined by Chi (1976) as

$$
K=\frac{D_{h p}^{2}}{2(f \mathrm{Re})_{l}}
$$


For the rectangular channels, Shah and Bhatti (1987) found that

$$
(f \mathrm{Re})_{l}=24\left(1-1.3553 a+1.9467 a^{2}-1.7012 a^{3}+0.9564 a^{4}-0.2537 a^{5}\right)
$$

It holds $0.05 \%$ error if $0<\mathrm{a}<1$. Following Faghri (1995) this equation is applicable to the configuration of HP grooves shown in Fig. 3.

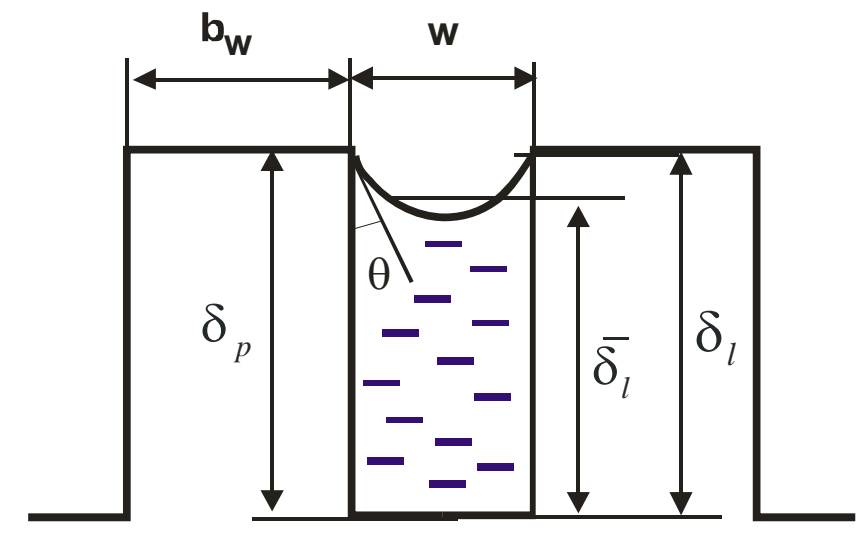

Figure 3. Groove configuration; the flooding corresponds to normal operation.

The components in Eqs. (9-11) are as follows

$$
D_{h p}=\frac{4 \bar{\delta} w}{2 \bar{\delta}+w}, \quad a=\frac{w}{\bar{\delta}}, \quad \varepsilon_{x}=\frac{w}{w+b_{w}}
$$

The mass conservation in the liquid channel cross section postulates that the change of the elementary volume $\left(A_{i} d x\right)$ of liquid in the grooves occurs due to the misbalance between entering-exiting axial liquid flow and evaporation-condensation rate from interface

$$
\rho_{l} \frac{\partial A_{l x}}{\partial t}=\frac{\partial \dot{m}_{l}}{\partial x}-j_{z} \pi D_{v} \varepsilon_{x}
$$

Where $A_{l x}$ is the HP cross-section area occupied with liquid (i.e. flooding), and $j_{z}$ is the mass flow rate of evaporation or condensation per unit of area of vapor-liquid interface in the grooves.

The liquid-vapor frictional interaction is described by the model, given by Schneider and DeVos (1980) for rectangular grooves and recommended by Faghri (1995) for grooved heat pipes.

$$
\begin{aligned}
& f_{l v}=\frac{\mu_{l} \dot{m}_{l} \psi}{A_{l x} \rho_{l} \varepsilon_{x} K} \\
& \psi=\frac{w^{3}}{6\left(w+b_{w}\right) D_{v}^{2}} \cdot(f \mathrm{Re})_{v} \frac{\mu_{v} \rho_{l}}{\mu_{l} \rho_{v}}\left[1-1.971 \cdot \exp \left(-\frac{\pi \delta_{l}}{w}\right)\right]
\end{aligned}
$$

Change in the liquid flooding, expressed via $A_{l x}$, causes change in the capillary pressure and consequently, change in the liquid pressure,

$$
P_{l}=P_{v}-\Delta P_{c}\left(A_{l x}\right)
$$

From the current axial profile of capillary pressure, defined by the degree of grooves flooding, the profile of axial mass flow rate can be restored. The important point is to define the capillary pressure as a function of the degree of flooding, $\Delta P_{c}\left(A_{l x}\right)$. 


\section{Groove flooding}

The effective height of the liquid column in the groove is associated with the flooding expressed via area $A_{l x}$. This area should be identified for all possible scenarios of the flooding. The simplest case is when the grooves flooding is full and meniscus is flat:

$$
\delta_{l}=\delta_{p}=\bar{\delta}_{l}, \quad A_{l x}=\pi D_{v} \varepsilon_{x} \bar{\delta}_{l}, \quad \Delta P_{c}=0
$$

When the evaporation occurs, or if a deficit of liquid charge takes place, a slight recession of liquid column in the groove happens and a meniscus radius is developed. The area occupied with liquid under the meniscus of radius $r_{m}$ can be derived through the segment area of the volume occupied with vapor above the meniscus.

$$
A_{v m}=\frac{1}{2} r_{m}^{2}(\pi-2 \theta-\sin (2 \theta))
$$

Where $\theta$ - is the wetting angle.

The meniscus radius is expressed through the wetting angle by

$$
r_{m}=\frac{w}{2 \cos \theta}
$$

The cross section area of liquid in the grooves for the case of normal meniscus recession, when the wetting angle value lies between its low limit $\left(\theta_{\min }\right)$ and $90^{\circ}$, can be expressed as

$$
A_{l x}=\left(w \delta_{p}-A_{v m}\right) N=\left(w \delta_{p}-w^{2} \Psi(\theta)\right) N
$$

Where

$$
\Psi(\theta)=\frac{(\pi-2 \theta-\sin (2 \theta))}{8 \cos ^{2}(\theta)}
$$

Note that in this case $\delta_{l}=\delta_{p}$ (see Fig.3).

The transcendent Eq. (20) can be solved numerically with respect to wetting angle to provide a function

$$
\theta=\theta\left(A_{l x}\right)
$$

The capillary pressure for grooves is derived from Laplace and Young equations and is a function of wetting angle, as it given by Chi (1976), and considering that the wetting angle is a function of the grooves flooding

$$
\Delta P_{c}=\frac{2 \sigma \cos \left(\theta\left(A_{l x}\right)\right)}{w}
$$

Consequently, Eq. (23) defines the needed relationship which links the capillary pressure and the degree of flooding, i.e. $\Delta P_{c}\left(A_{l x}\right)$.

Besides the case of normal meniscus formation developing, when the wetting angle does not reach its minimal value, the following cases are also considered: over-flooding (Fig.4a), liquid column recession when the wetting angle reaches its low limit (Fig. 4b), partial drying (Fig. 4c,d) and complete dry-out. 


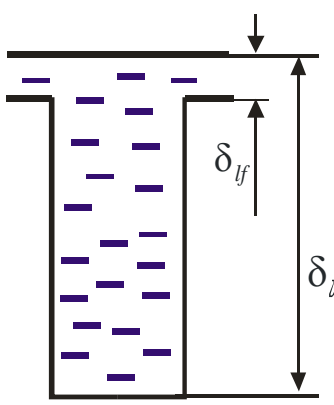

a)

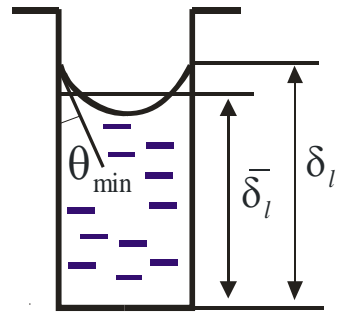

b)

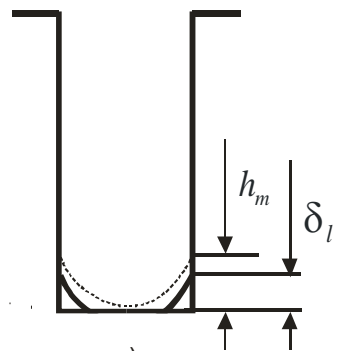

c)

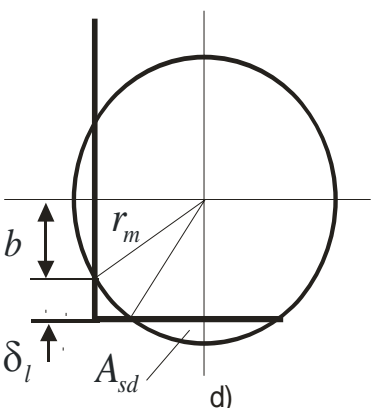

d)

Figure 4. Cases of abnormal flooding

On the excess of liquid (over-flooding, Fig. 4a), the thickness of liquid film that covers the grooves, is easily obtained through

$$
\delta_{l f} \equiv \delta_{l}-\delta_{p}=\frac{1}{2}\left(D_{v}-\sqrt{D_{v}^{2}-\frac{A_{l x}}{\pi}+4 \frac{\delta_{p} N w}{\pi}}\right)
$$

The over-flooding provides the effect of reduction of cross section area available for vapor flow. The capillary pressure at the surface where the over-flooding takes place is near zero.

On the event of liquid column recession (Fig. 4b) the wetting angle holds its minimal value. The maximal and average liquid column heights are expressed as

$$
\begin{aligned}
& \delta_{l}=\frac{A_{l x}}{N \varepsilon_{x} w}+w \Psi\left(\theta_{\min }\right) \\
& \bar{\delta}_{l}=\frac{A_{l x}}{w}
\end{aligned}
$$

The reduced flooding takes effect on the permeability and effective thermal conductance from the HP wall to the vapor-liquid interface. The capillary pressure reaches its maximal magnitude

$$
\Delta P_{c}=\frac{2 \sigma \cos \left(\theta_{\min }\right)}{w}
$$

If further reducing the liquid column takes place, the meniscus can touch the bottom of the groove. On this event the grooves are considered as partially dried; the height of liquid column reaches the height of the vaporoccupied segment above the liquid meniscus (Fig. 4c)

$$
\delta_{l} \leq h_{m}=w \Phi\left(\theta_{\min }\right)
$$

Where

$$
\Phi(\theta)=\frac{1}{2}(\sec (\theta)-\tan (\theta))
$$

The cross section area of liquid in the groove is restored from the geometry shown in Fig 4d. The geometry construction yields the following set of equations 


$$
\left\{\begin{array}{l}
\frac{A_{l x}}{N}=\left(\delta_{l}+b\right)^{2}-\frac{1}{4} \pi r_{m}^{2}+2 A_{s d} \\
b=r_{m} \cdot \tan \left(\theta_{\min }\right) \\
w=2\left(\delta_{l}+b\right) \\
A_{s d}=\frac{r_{m}^{2}}{4}\left(\frac{\theta_{\min }}{2}-\sin \left(\frac{\theta_{\min }}{2}\right)\right)
\end{array}\right.
$$

This set is solved with respect to the liquid column $\delta_{l}$ by elimination of $\left\{A_{s d}, b, r_{m}\right\}$ and therefore yielding the necessary function of area, $\delta_{l=} \delta_{l}\left(\mathrm{~A}_{\mathrm{lx}}\right)$ :

$$
\delta_{l}=\frac{w}{2}\left(1-\frac{2 w A_{l x} \tan ^{2}\left(\theta_{\min }\right)}{N \sqrt{A_{l x} w^{2}\left(\pi+\theta_{\min }-2 \sin \left(\frac{\theta_{\min }}{2}\right)\right) \tan ^{2}\left(\theta_{\min }\right)}}\right)
$$

The average height of the liquid column is expressed by Eq. (26).

On the fully dried grooves, a microfilm of adsorbed liquid is kept over the entire groove surface,

$$
\delta_{l}=\bar{\delta}_{l}=\delta_{m c l}
$$

In the model the capillary pressure over fully dried domains is kept maximal, as it expressed by Eq. (27), in order to provide a possibility to simulate the eventual re-wetting following the full dry-out.

After definition of the parameters of all possible cases of flooding, the conservation of mass of liquid in the grooves is obtained from considering the dynamics of grooves flooding. The following instantaneous mass balance must be kept over entire length of the HP.

$$
\frac{d\left(N L \rho w \int_{0}^{L} \bar{\delta}_{l} d x\right)}{d t}=\frac{\pi D_{v}}{2} \int_{0}^{L} j_{z} d x
$$

We suggest the uniform initial distribution of the area of liquid that is completely defined by the liquid charge mass $M_{0}$

$$
\left.A_{l x}(x)\right|_{t=0}=\frac{M_{0}}{\rho_{l} L}
$$

\section{Mass and momentum balance for vapor flow}

The mass conservation along HP axis in vapor core is defined by

$$
D_{v} \frac{d(\rho u)_{v}}{d x}=4 j_{z}
$$

Integrating from 0 to the current position gives vapor axial velocity profile

$$
(\rho u)_{v x}=\frac{4}{D_{v}} \int_{0}^{x} j_{z} d x
$$

The density distribution is obtained by the pressure profile. The momentum balance for vapor flow expressed in the terms of mass flow rate is defined by 


$$
\frac{\partial\left(\rho u^{2}\right)_{v}}{2 \partial x}=-\frac{\partial P_{v}}{\partial x}+\tilde{f}_{v x}
$$

This equation is solved to find the vapor pressure profile, related to a reference point, where the meniscus is flat. The viscosity component is determined in depends of laminar or turbulent flow occurrence

$$
\tilde{f}_{v x}=\frac{32 \mu_{v} u_{v}}{\left(D_{v}-2 \delta_{l f}\right)^{2}} \quad \text { or } \quad \tilde{f}_{v x}=\xi \frac{\rho_{v} u_{v}^{2}}{\left(D_{v}-2 \delta_{l f}\right)}
$$

First term is derived from the Darcy's law for laminar flow and second - from Weisbach equation. The above model was used by Faghri and Parvani (1987), who validated it by comparison with the Busse (1967) model. For the turbulent flow, the generalized relationships for friction coefficient $\xi$ are used (Isachenko et al., 2000).

The absolute pressure is obtained as the saturation pressure picked at the reference point. This point is defined by investigation of the current profile of liquid pressure. The location where the pressure is maximal is marked as current reference point; the saturation pressure in this point is obtained from the temperature at the vapor-liquid interface given by energy balance.

$$
\begin{aligned}
& x_{r e f}=\left.x\right|_{\max _{x}\left(P_{1}\right)} \\
& P_{v}\left(x_{\text {ref }}\right)=P_{l}\left(x_{\text {ref }}\right)=P_{\text {sat }}\left(T_{\text {if }}\left(x_{\text {ref }}\right)\right)=P_{\text {ref }}
\end{aligned}
$$

We suggest that in this point the most flat meniscus is developed, and the liquid pressure is most close to saturated pressure. So, this point yields the reference pressure $P_{\text {ref }}$, needed to obtain the absolute vapor pressure instant profiles over HP length. In the numerical procedure, the vapor profile is shifted to match the vapor pressure to one at the reference point. The liquid pressure profile is adjusted using Eq. (16). Usually, one-two iterations are needed to stabilize the profiles at each fast time step.

\section{Model verification and numerical aspects}

The numerical model used in this work has been validated by comparison with the test results, presented by Schlitt et al. (1975) for performance ground tests of an ammonia groove HP for two cases of different average work temperature. To perform this analysis, the HP sub-model was derived from the present model of the HP assembly by the excluding the conductances to honeycomb panel elements. The input parameters of the HP in the model were modified to be consistent to ones used in the experiment. Moreover, the external conditions were adjusted to ones imposed in the experiment. No attached mass was considered and steady state mode was simulated. At each inclination, several attempts with gradually increased heat load had been performed until the capillary limit violation, when the dry-out is detected. The comparative results are shown in Fig. 5.

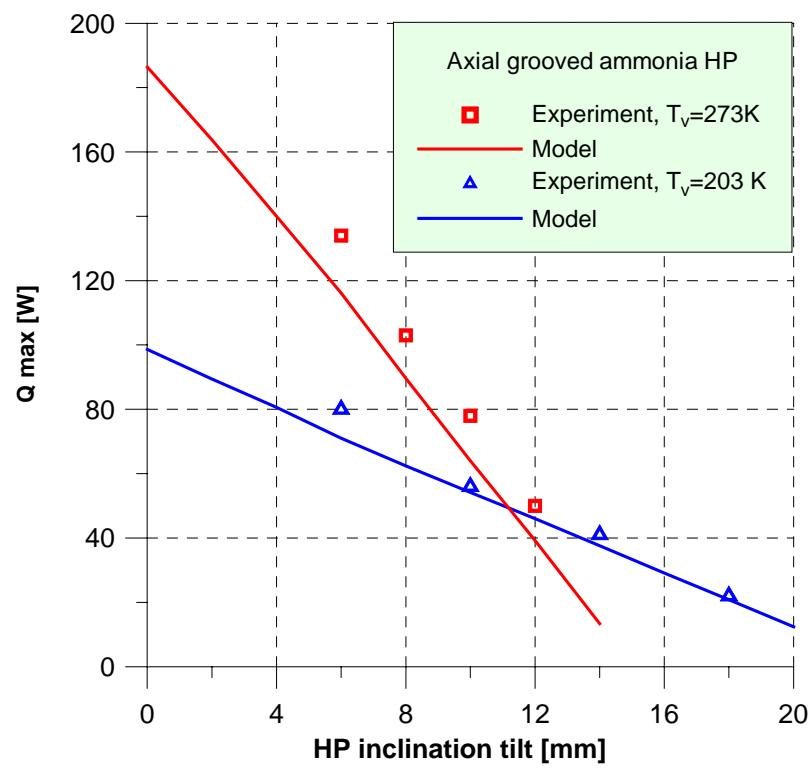

Figure 5. Comparison with the experimental results. 
The disagreement in $\mathrm{Q}_{\max }$ values lies within 8 \% for adverse inclinations below 4 degrees.

The numerical procedure has the following particulars. The "floating internal point" conditions at the reference point are transformed to the left-bound conditions by a special procedure. The predictor-corrector technique with fixed time step is used for integrating the system of ordinary differential equations of the energy balance. Two 1D numerical overlapped grids are established: one - for control volume-related parameters: temperature, pressure, radial mass flow rates; and second - for control volume interface-related parameters: velocity, axial mass flow rate. Two time scales have been used: slow - for energy balance equations at the level of panel and fast - for momentum and mass conservations inside the HP. Within each slow time step $\Delta \tau$, fast steps of 0.03 secs are used to compute the fluid motion parameters, taking the temperatures as frozen. A relaxation up to 0.04 was used to reach the numerical stability in the fast time scale. The fast time iterations stop when the quasi steady state is achieved within the slow time step.

\section{Result of the modeling}

The model was used to simulate the behavior of the HP assembly in space conditions. The external fluxes are calculated for a circular orbit of $750 \mathrm{~km}$ of altitude and inclination of $20^{\circ}$. External face panel coating is TeflonAl film of 125 mkm of thickness to provide low absorptivity and high emissivity. Figure 6 presents the implied external heat fluxes along the orbit.

The HP honeycomb panel fragment measures width of $0.22 \mathrm{~m}$ and length of $1 \mathrm{~m}$. Three equipment boxes are attached to the panel in positions between the HP marks of 0-200 mm, 400-600 mm and 750-850 mm. Main input data for modeling are presented in Table 1.

Table 1. Input data for modeling.

\begin{tabular}{|l|l|}
\hline Absorptivity of coating & 0.15 \\
\hline Effective conductivity of honeycomb & $6 \mathrm{~W} / \mathrm{m} / \mathrm{K}$ \\
\hline Emissivity of coating & 0.85 \\
\hline Height of metal rib & $1 \mathrm{~mm}$ \\
\hline Length of HP & $1000 \mathrm{~mm}$ \\
\hline Mass of HP fluid charge & $20 \mathrm{~g}$ \\
\hline HP mass per length & $0.4 \mathrm{~kg} / \mathrm{m}$ \\
\hline Mass of equipment 1,2,3 & $0.5 ; 0.3 ; 02 \mathrm{~kg}$ \\
\hline Material for panel face sheets & $\mathrm{Al} 2024$ \\
\hline Material of HP & $\mathrm{Al} 6063$ \\
\hline Number of HP grooves & 20 \\
\hline Thickness of bottom panel sheet & $0.8 \mathrm{~mm}$ \\
\hline Thickness of upper panel sheet & $1.2 \mathrm{~mm}$ \\
\hline Vapor channel diameter of HP & $16 \mathrm{~mm}$ \\
\hline Width of HP groove & $1 \mathrm{~mm}$ \\
\hline Width of HP profile & $20 \mathrm{~mm}$ \\
\hline
\end{tabular}

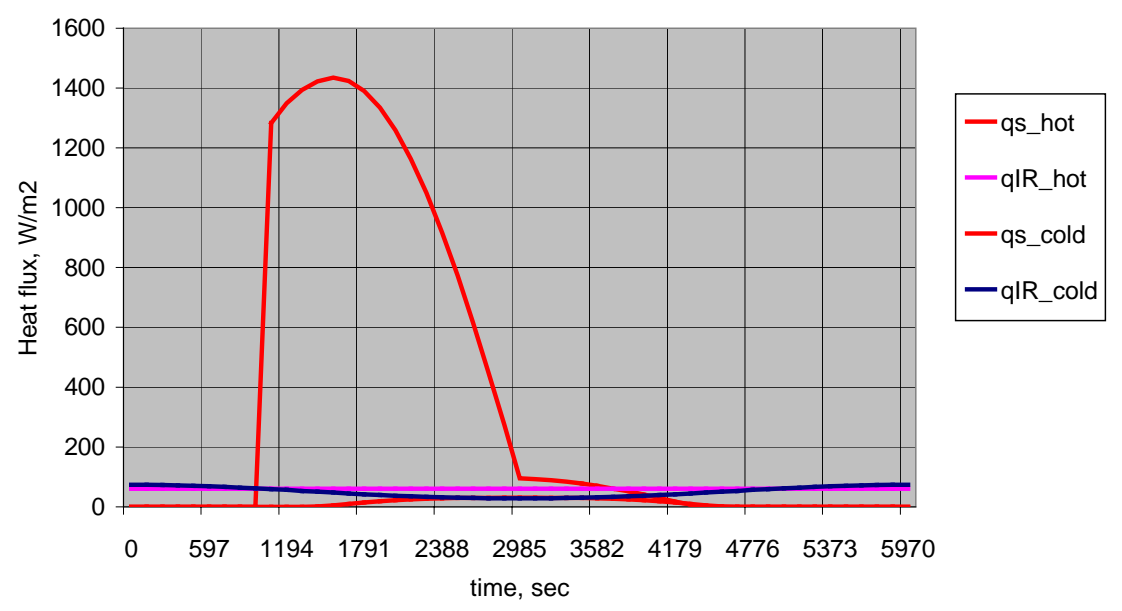

Figure 6. External fluxes on the panel for cold and hot cases as a function of orbit time. 
The hot and cold cases of incident external fluxes were simulated for all 3 equipment switched-on for normal mode of operation $\left(\mathrm{Q}_{1}=15 \mathrm{~W}, \mathrm{Q}_{2}=10 \mathrm{~W}\right.$ and $\mathrm{Q}_{3}=15 \mathrm{~W}$, from left to right in the figures). The results were obtained for two working fluids - acetone and ammonia. Figure 7 shows the hot case temperature profiles along the $\mathrm{HP}$ axis during the $2^{\text {nd }}$ orbit after starting up from $20{ }^{\circ} \mathrm{C}$.

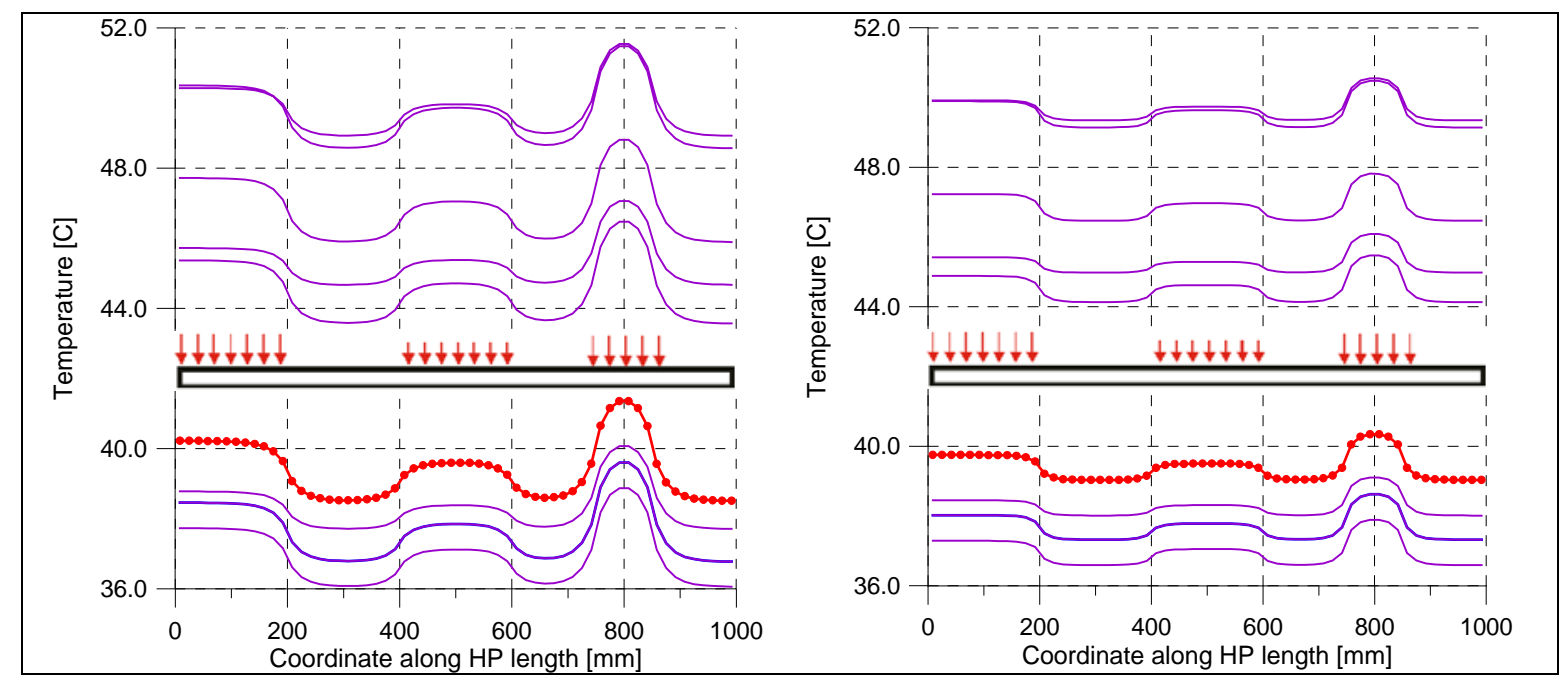

Figure 7. Temperature $T_{w}$ profiles along the HP axis for acetone (left) and ammonia (right) for the hot case.

After two orbits, the temperature $T_{w}$ varies along HP length within the range from 38.5 to $41.4{ }^{0} \mathrm{C}$ for the $\mathrm{HP}$ charged with acetone and within 39.3 to 40.3 for ammonia (dotted line). The results confirm that in terms of the temperature homogeneity, the difference between acetone and ammonia HPs is very small, in order of $1^{0} \mathrm{C}$. Inorbit temperature variation is also almost the same for two fluids, from about $36 . . .37$ to $51 . .52{ }^{0} \mathrm{C}$.

Figures 8 and 9 demonstrate the instant profiles of main HP work parameters along the acetone HP length, captured during the $2^{\text {nd }}$ orbit for the hot case with the intervals of about 600 sec. First profile is indicated by thick line; the last one is the dotted line; intermediate profiles - are thin lines. The profiles of axial liquid mass flow rate factored by the latent heat are shown in the left graph of Fig.8. Radial heat fluxes are displayed on the right graph; positive flux corresponds to the evaporation and negative - the condensation.

The wetting angle profiles are shown in Fig.9, in the left graph. The near $90^{0}$ limit of $89.5^{0}$ was set to detect the complete flooding of the grooves. So, the flat pattern of the profiles at this level defines either complete flooding or over-flooding. It is interesting to note that there are two locals of over-flooding along the HP length were detected: one is at the right HP end cup, that is usual, and second - is in the near-middle position, at the mark of about $350 \mathrm{~mm}$, on the left from the Equipment 2. Vapor comes from opposite directions to this location, and the condensation rate here first is higher than the rate of liquid outflow to the opposite zones of evaporations. Then the meniscus approach the flatness, the over-flooding occurs and yields the reduction of the local condensation rate until equilibrium is reached.

The right graph in Fig. 9 shows the local height of the liquid column in the groove. Degree of two over-flooding is different for two locals, which varies depending on external conditions. In some periods along the orbit time the middle over-flooding disappears. A small rectangle graph in the center of the left graph shows the temperature variation of the all three equipment boxes during the second orbit.

The cold case corresponds to twice-reduced heat dissipation of equipment and minimal external heat fluxes. The result profiles of temperature $T_{w}$ and vapor axial velocity are shown in Fig.10; the results are given for the $2^{\text {nd }}$ orbit after HP start-up from $-10{ }^{\circ} \mathrm{C}$. 


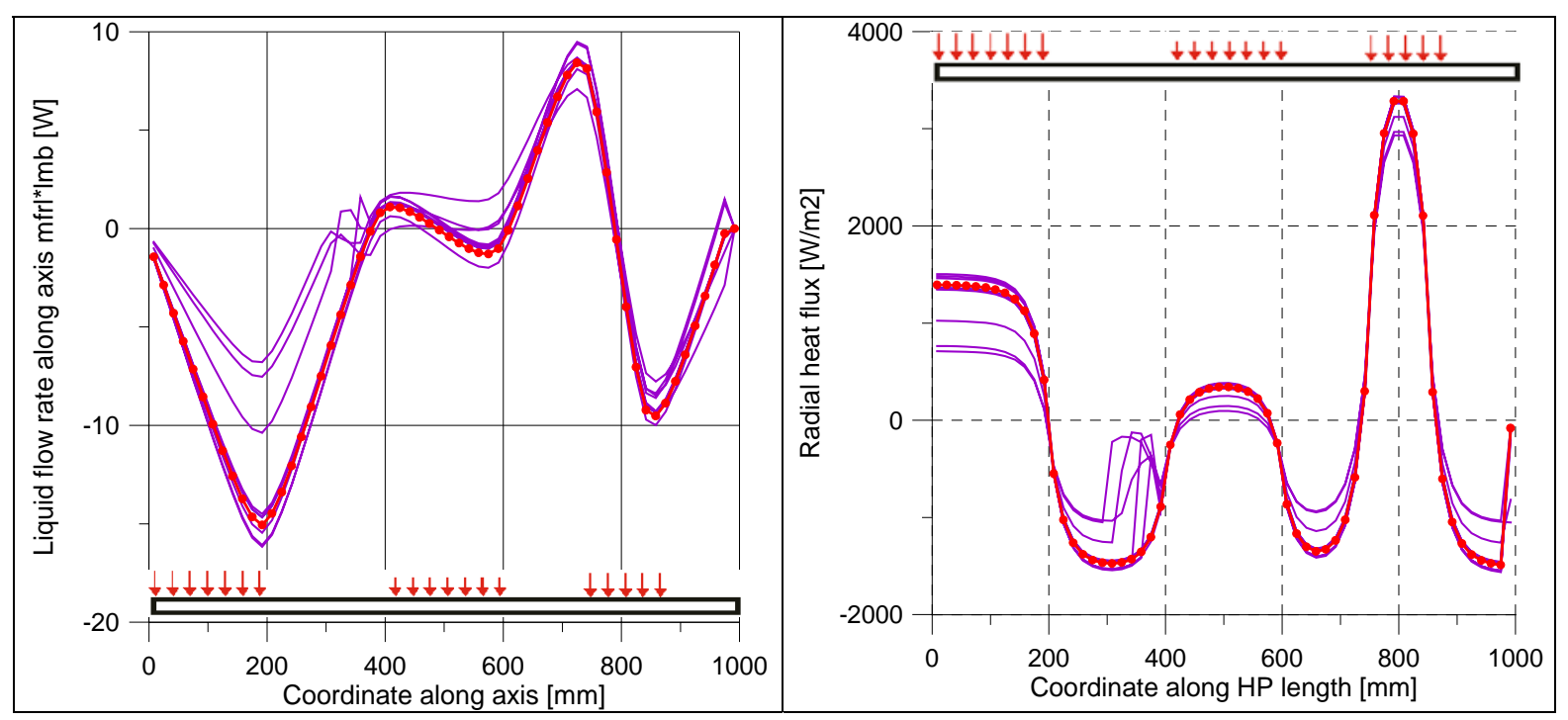

Figure 8. Profiles of liquid axial mass flow rate (left) and radial heat flux (right) of acetone HP for the hot case.
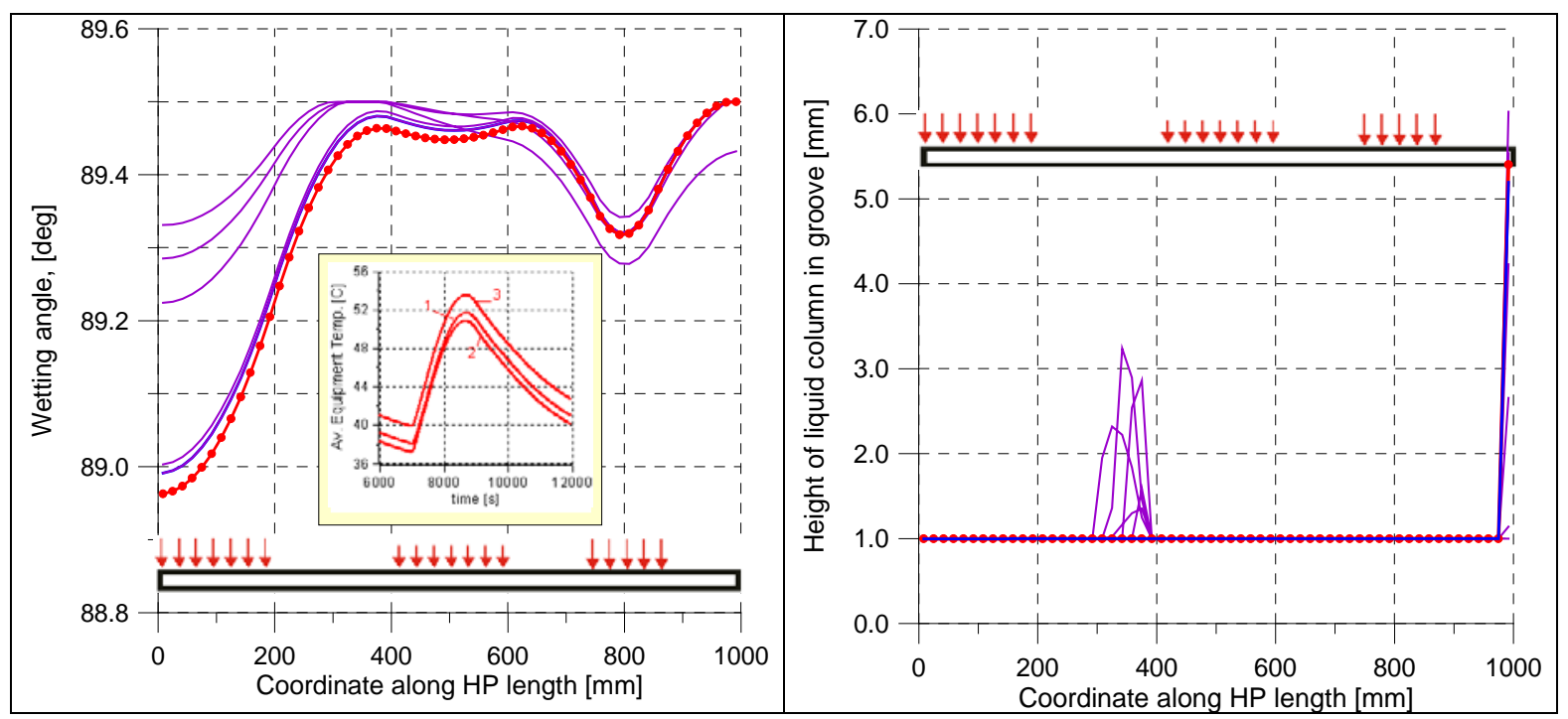

Figure 9. Profiles of wetting angle (left) and liquid height in grooves (right) of acetone HP for the hot case.
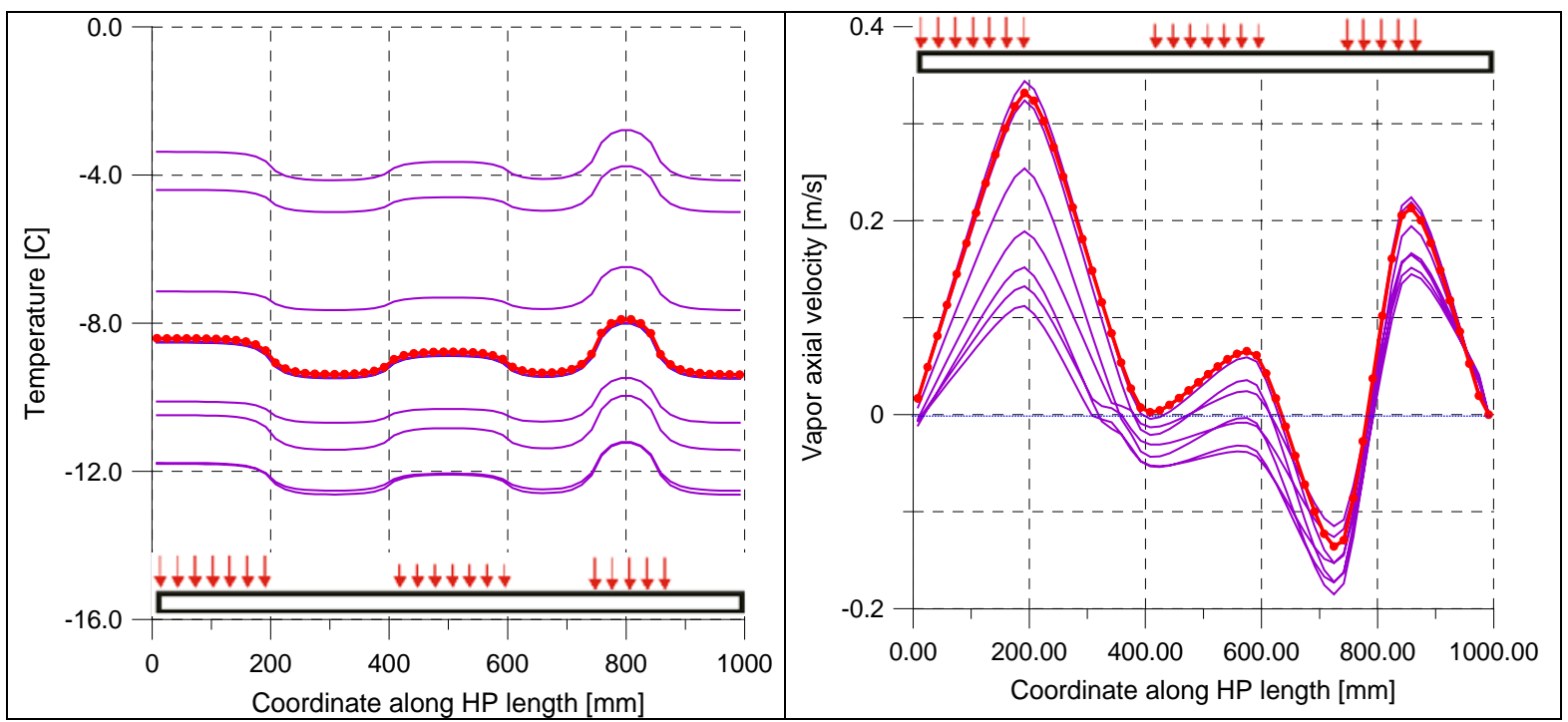

Figure 10. Profiles of $T_{w}$ and axial vapor velocity of acetone HP for the cold case. 
The next case for simulation was the study of the behavior of HP under possible scenarios of so-named satellite contingency modes, when a failure occurs, and satellite is almost completely switched-off. This mode causes all temperatures to decrease below the operational limits of equipment. The farther surviving of satellite depends on a possibility of normal operation recuperation. If it is happened, the full electric power returns back and the equipments and heaters are switched-on. In this situation the HPs have to start up successfully from the subcooled state and do not provoke any new failures.

The following possible scenario was simulated. The reduced power of $7.5 \mathrm{~W}$ is switched from 1 st to 3rd equipment in the middle of the $2^{\text {nd }}$ orbit, with the second equipment switched-off all time. Such an interswitching makes the inversion of the liquid and vapor flow directions during the transient.

Figure 11 shows the result temperature profiles under such a transient during the $2^{\text {nd }}$ orbit after start-up from -40 ${ }^{0} \mathrm{C}$, obtained for two different working fluids. At the end of the $2^{\text {nd }}$ orbit, the temperature varies within -46.9 to $47.5{ }^{0} \mathrm{C}$ along the ammonia HP, whereas along the acetone HP the temperature does within -46.3 to $-47.7^{0} \mathrm{C}$. Therefore, the spreading characteristic of the acetone HPs at cold temperatures is almost the same as the ammonia HPs. Temperature change of all 3 equipment along time for the acetone HP is shown in the left graph of Fig. 12.

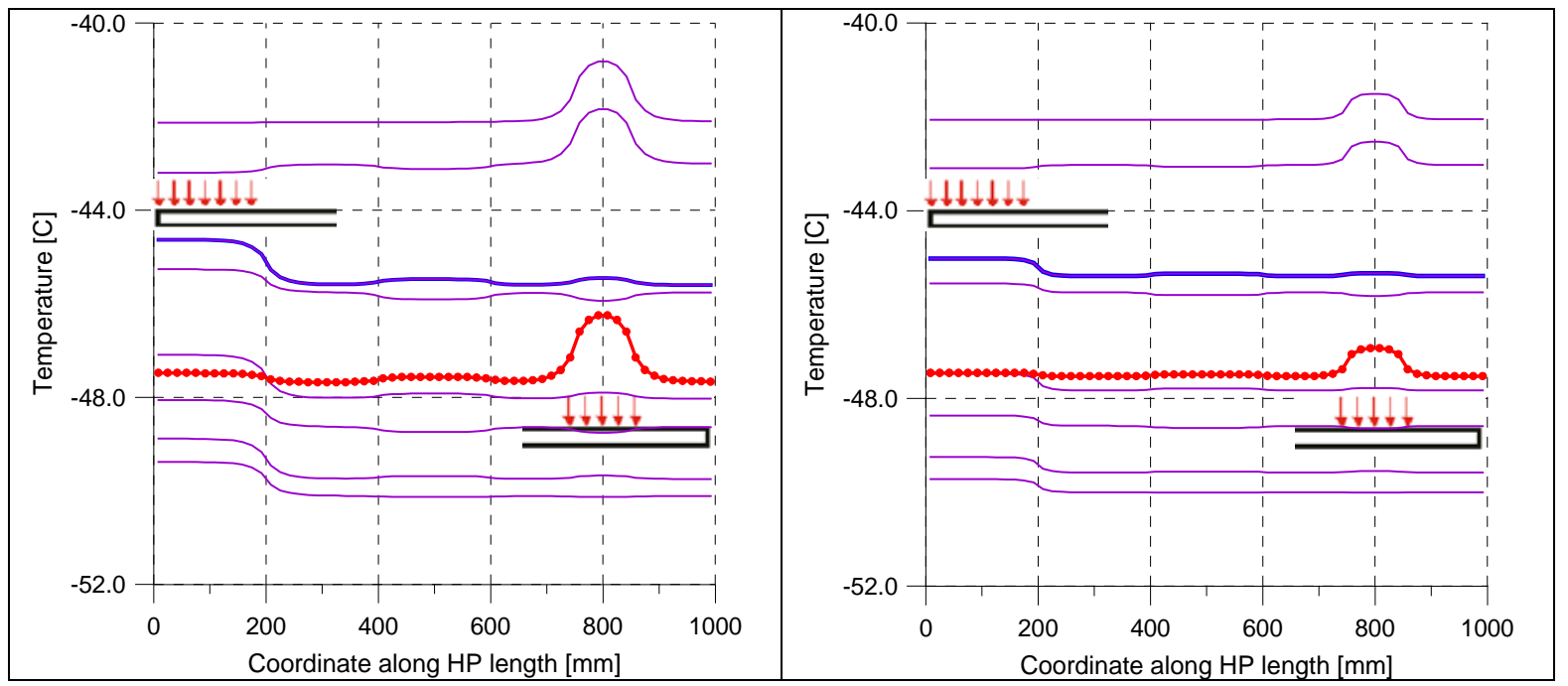

Figure 11. Profile of temperature Tw on the event of inter-switch from $1^{\text {st }}$ to $3^{\text {rd }}$ equipment for acetone (left) and ammonia (right) HP for the cold case.

Figure 13 demonstrates the profiles of other parameter variations on the same event of equipment power interswitching. Under such cold temperatures the acetone vapor velocity is still far from its sonic limit, and wetting angle is also far from its minimum value of $\sim 7^{0}$.
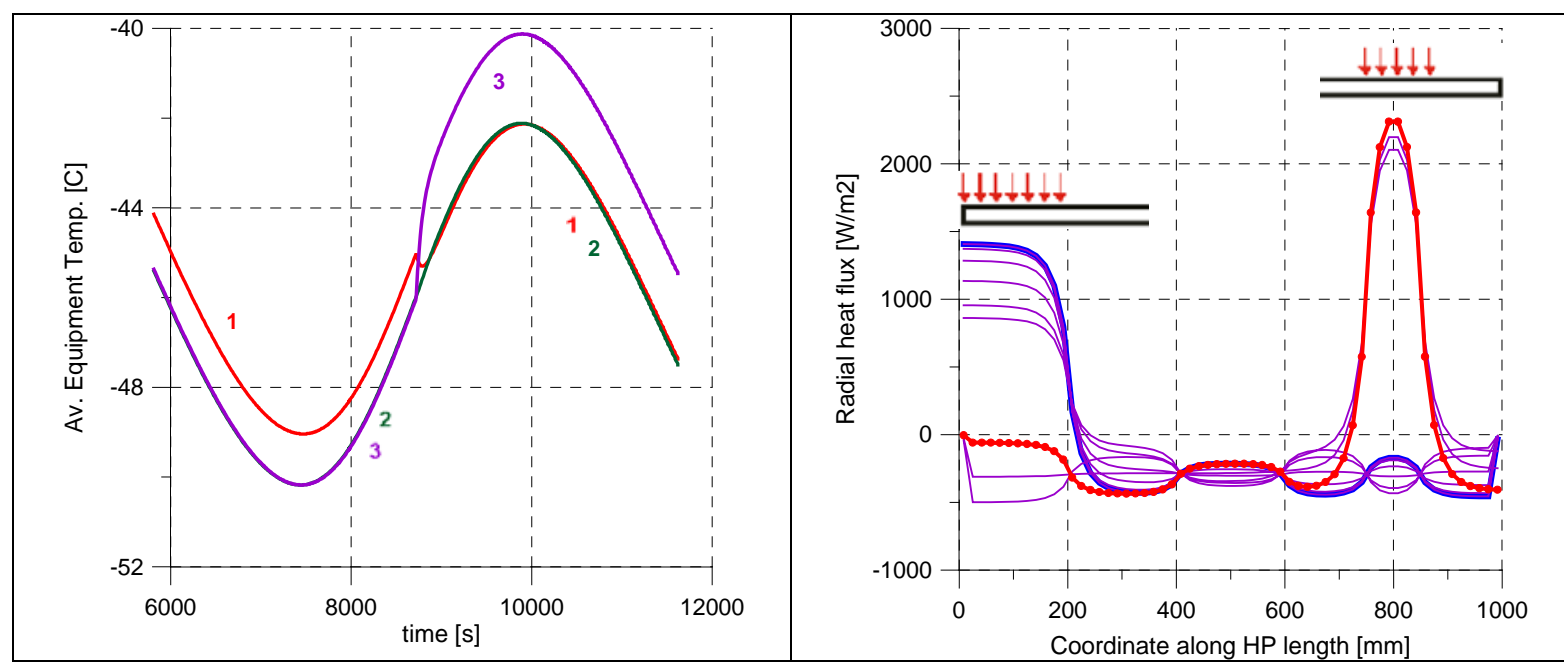

Figure 12. Temperature change (left) and radial heat flux profiles (right) on the inter-switching event for acetone HP. 


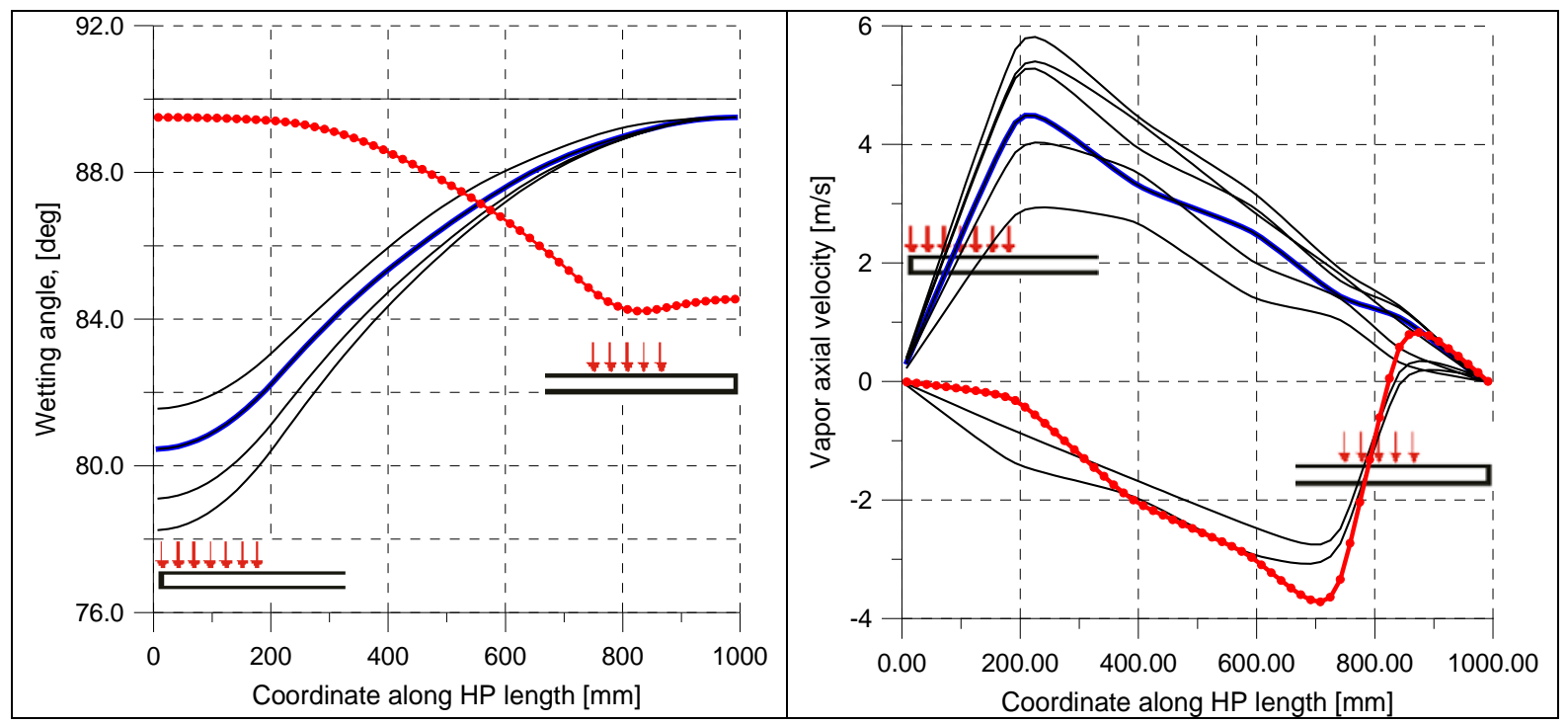

Figure 13. Profiles of the wetting angle and vapor velocity on the same event for acetone $H P$.

The next case for simulation was a contingency start-up from $-60{ }^{\circ} \mathrm{C}$ by switching-on the second equipment (or a heater on it). Figure 14 (left graph) shows the wetting angle profiles captured with the interval of about 33 sec from the cold start-up of the acetone HP. The heat load of $20 \mathrm{~W}$ was applied at the HP central zone $\left(2^{\text {nd }}\right.$ equipment location) to get the start-up. As it seen from Fig. 14, soon after the heat load applying, a local dry-out occurs. After about 6 minutes of heating, a re-wetting takes place and HP starts to operate normally.

Then two cases of HP fluid mass charging were simulated: The charging of $20 \mathrm{~g}$ corresponds to the exact charging with no fluid excess at $20{ }^{\circ} \mathrm{C}$, whereas the $23 \mathrm{~g}$ charge - is a practice recommended excess of $15 \%$. The same scenario of the cold start-up in term of wetting angle behavior is presented in Fig. 14, where left graph corresponds to the charge of $20 \mathrm{~g}$ of acetone and right graph - to $23 \mathrm{~g}$. As it seen from the figure, there is no notable difference in the cold start-up behavior due to the excess of fluid charging. This result is not obvious, because intuitively it seems that the more overcharging, the less chance of a temporary dry-out during start-up.

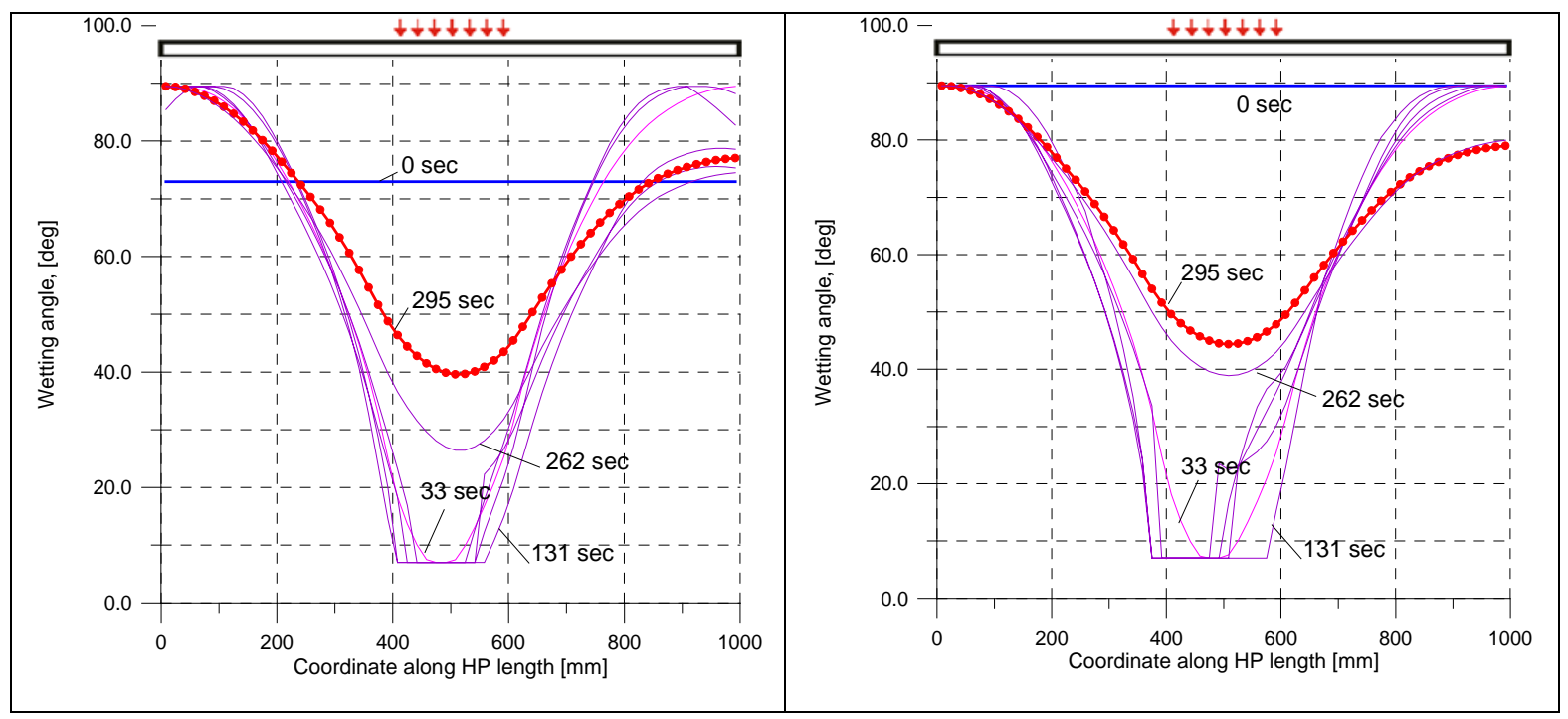

Figure 14. Wetting angles profiles on the cold start-up of acetone $\mathrm{HP}$ from $-60{ }^{\circ} \mathrm{C}$; left - charging of 20 -g and right - 23 .

For the comparison purpose, a start-up under the same conditions was simulated for the case when the HP was charged with ammonia. Figure 15 shows the wetting angle and temperature instant profiles captured with the same interval of time at the start-up. Because of superior thermo-physical properties of ammonia, no local dryout occurrence during the start up was detected. The spreading capability, evaluated through the difference between maximal and minimal temperatures along the HP length, is also excellent, as one can see from Fig. 15, right picture. 


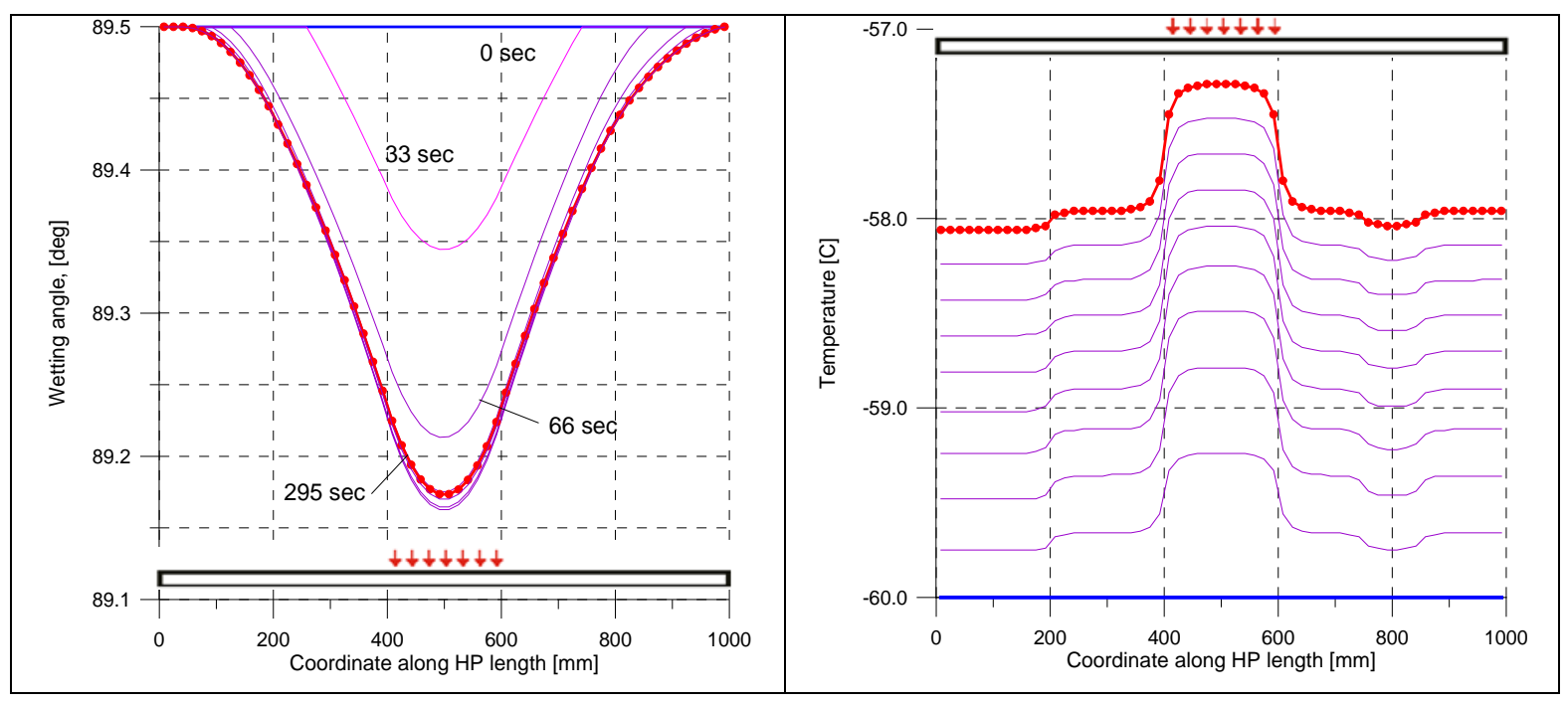

Figure 15. Wetting angles (left) and temperature profiles (right) on the cold start-up for ammonia HP.

The acetone HP demonstrates an inferior temperature spreading capability at the cold start up, as it can be observed from Fig. 16, left picture. However, in the situation of equipment recuperation from a cold nonoperational temperature, what is more important is the rate of equipment temperature increasing. The right picture of Fig. 16 shows the equipment warming up rate for the cases of either acetone or ammonia HP using.

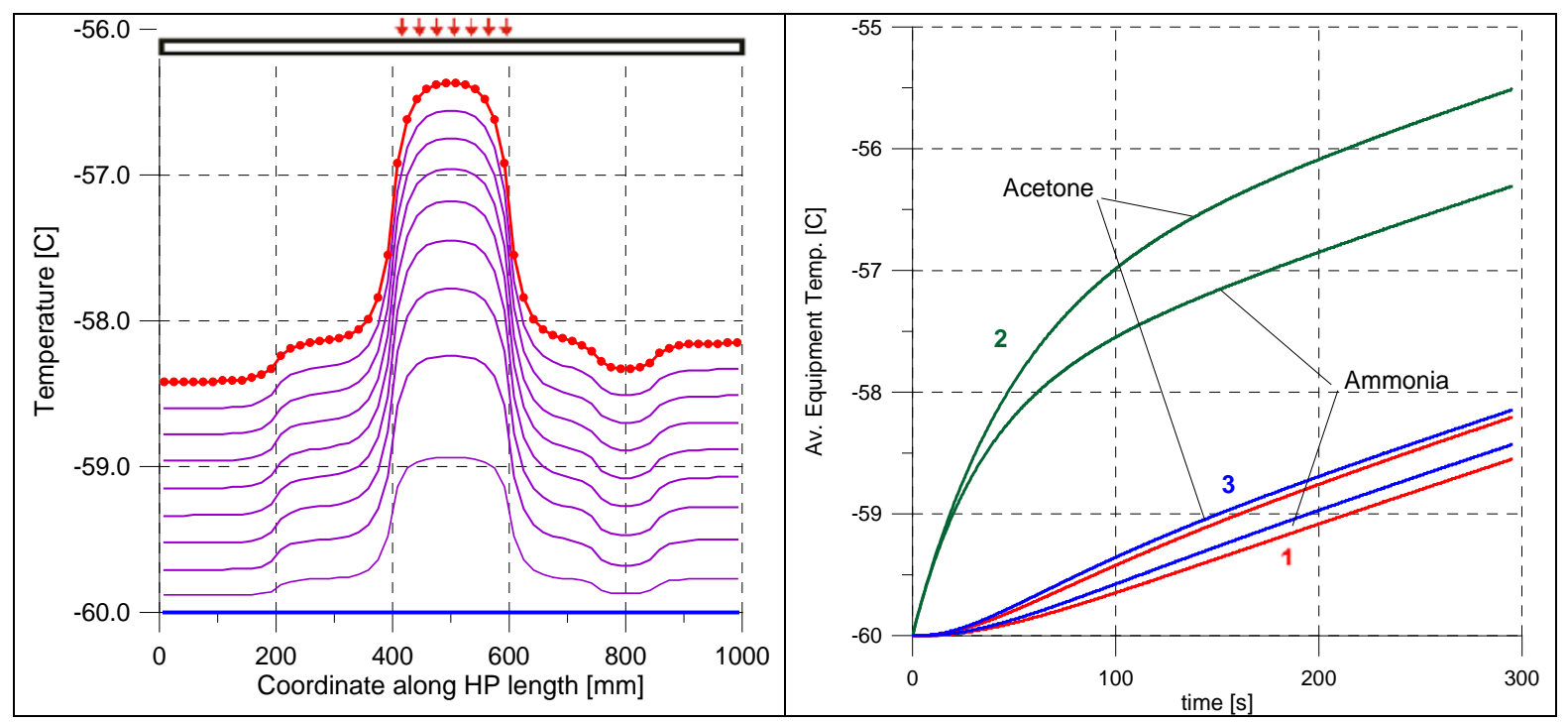

Figure 16. Temperature profiles (left) and equipment recuperating heat-up if acetone or ammonia HP is used (right).

As it seen from the figure, the rate of the equipment warming up is slight better for the acetone HP than for ammonia one. It is explained by the evidence that the temporary local HP dry-out in the region of the equipment location contributes to the accelerated heating for the acetone HP.

\section{Conclusions}

The mathematical model of a grooved heat pipe is presented. The model is developed to simulate transient performance of HPs in the cases of application when neither number nor location of evaporator and condenser sections is defined a priori. The model was validated by published experimental data of laboratory tests of an ammonia HP under different temperatures. The peculiarity of the model is that the flooding of grooves is continuously monitored and the capillary pressure is defined as a function of degree of groove flooding. Such approach permits straightforward simulation such events as start-up, partial drain of grooves, local dry-out, rewetting and over-flooding. Numerical procedure is adopted to tackle the HP capillary limit violations without any interruption of the integration process. These features allow the designer to evaluate if heat pipes operate within its limits under any combination of external factors, taking into account the value of fluid charge. It is also 
possible as to simulate the consequents of temporary limit violations because of the system-level failure or contingency and evaluate the possibility and conditions of HP normal operation recuperation.

The HP model was used to simulate the HP performance in the honeycomb panel under the Space hot and cold conditions. The cases of start-up, equipment switching-on and switching-off were simulated and studied. No notable difference in the heat spreading capability for ammonia and acetone HP was observed for normal operational modes under the hot and cold conditions.

Under contingency cold condition the acetone HP operates well in spite of low vapor density. For the cold startup from $-60{ }^{0} \mathrm{C}$ the initial dry-out is recuperated in about 6 minutes and then the HP starts to operate normally. The temporary local dry-out for the acetone HP somewhat contributes to the accelerated recuperation of the equipment from the extreme cold temperature, compared to the case if the same HP were charged with ammonia.

\section{References}

Baturkin, V., Zhuk, S., Vojta, J., Lura, F., Biering, B., Loetzke, H-G., 2002, “Elaboration of Thermal Control System on the Base of Heat Pipes for Micro Satellites Magion 4, 5 and BIRD”, Proc. of the 12th International Heat Pipe Conference, Moscow-Kostroma, Russia, 19-24 May, 2002, pp. 264-269.

Bienert, W.B., Skrabek, E.A., 1972, “Heat Pipe Design Handbook”, Dynatherm Corp. Report to NASA, NASACR-134264, Contract No NAS9-11927, Chapter D, pp. D31-D40.

Chi, S.W., 1976, “Heat Pipe Theory and Practice”, Hemisphere Publishing Corporation, pp. 33-95.

Faghri A., 1995, “Heat Pipe Science and Technology”, Taylor \& Francis, pp. 61-264.

Faghri A., Parvani S., 1988, "Numerical Analysis of Laminar Flow in a Double-Walled Annular Heat Pipe”, AIAA J. Thermophysics and Heat Transfer, Vol. 2, No. 3. pp. 165-171.

Isachenko V.P. and Sukomel A.S. A., 2000, “Heat Transfer”, ISBN: 089875027X, International Law \& Taxation.

Mikheyev, A., Loginov, N., Michurin, D., 2002, "Mathematical Model and Experimental Investigation of Transient Behavior of Heat Pipe”, In: Yu. Maidanic (Ed), "Heat Pipes: Science Technology Application, Proceeding of 12th International Heat Pipes Conference”, Russia, pp. 494-502.

Peterson, G.P., 1994, “An Introduction to Heat Pipes: Modeling, testing, and Applications”, John Wiley \& Sons, Inc., pp. 44-159.

Schlitt, K.R., Brennan, P.J. Kirkpatrick, J.P., 1975, "Parametric performance of Extruded Axial grooved Heat Pipes from 100o to 300 oK," In: "Progress in Astronautics and Aeronautics: Heat Transfer with Thermal Control Applications”, Vol. 39, pp. 215-227.

Schlitt, R., 1995, "Performance Characteristics of Recently Developed High-Performance Heat Pipes”, Heat Transfer Engineering, Vol. 16, N 1, pp. 44-52.

Schneider, G.E., DeVoz, R., 1980, "Nondimensional Analysis for the Heat Transport Capability of AxiallyGrooved Heat Pipes Including Liquid/Vapor interaction”, AIAA Paper No 1980-0214, 18th Aerospace Sciences Meeting, Pasadena, Calif., Jan. 14-16, pp. 1-10.

Shah, R.K., Bhatti, M.S., 1987, “Laminar Convective Heat Transfer in Ducts”, in: S. Kakac, R.K. Shah, W. Aung (Eds.), "Handbook of Single-Phase Convective Heat Transfer”, Wiley, New York, Chapter 3, pp. 3.1137.

Tournier, J.-M., El-Genk, M.S., 1994, “A heat pipe transient analysis model”, International Journal of Heat and Mass Transfer, Vol. 37, N 5, pp. 753-762.

Vargaftik, N.B. Vinogradov, Y.K, Yargin, V.S., 1996, "Handbook of Physical Properties of Liquids and Gases”, Begell House, Inc., NY, Wallingford (UK), 3rd edition, pp. 747-853.

Vlassov, V.V. Sousa, F.L, Takahashi, W.K., 2006, “Comprehensive Optimization of a Heat Pipe Radiator Assembly filled with Ammonia or Acetone”, International Journal of Heat and Mass Transfer, Vol. 49, N 23-24, pp 4584-4595.

Vlassov, V.V., 2005, “Transient Model of a Grooved Heat Pipe Embedded in the Honeycomb Structural Panel”, SAE Paper 2005-01-2936, International Conference on Environmental Systems (ICES), 11-14 July, Rome, Italy. 